\title{
Muscle cell identity requires Pax7-mediated lineage-specific DNA demethylation
}

\author{
Elvira Carrió ${ }^{1}$, Alessandro Magli ${ }^{2}$, Mar Muñoz ${ }^{1}$, Miguel A. Peinado ${ }^{1}$, Rita Perlingeiro ${ }^{2}$ and Mònica Suelves ${ }^{1 *}$
}

\begin{abstract}
Background: Skeletal muscle stem cells enable the formation, growth, maintenance, and regeneration of skeletal muscle throughout life. The regeneration process is compromised in several pathological conditions, and muscle progenitors derived from pluripotent stem cells have been suggested as a potential therapeutic source for tissue replacement. DNA methylation is an important epigenetic mechanism in the setting and maintenance of cellular identity, but its role in stem cell determination towards the myogenic lineage is unknown. Here we addressed the DNA methylation dynamics of the major genes orchestrating the myogenic determination and differentiation programs in embryonic stem (ES) cells, their Pax7-induced myogenic derivatives, and muscle stem cells in proliferating and differentiating conditions.

Results: Our data showed a common muscle-specific DNA demethylation signature required to acquire and maintain the muscle-cell identity. This specific-DNA demethylation is Pax7-mediated, and it is a prime event in muscle stem cells gene activation. Notably, downregulation of the demethylation-related enzyme Apobec2 in ES-derived myogenic precursors reduced myogenin-associated DNA demethylation and dramatically impaired the expression of differentiation markers and, ultimately, muscle differentiation.

Conclusions: Our results underscore DNA demethylation as a key mechanism driving myogenesis and identify specific Pax7-mediated DNA demethylation signatures to acquire and maintain the muscle-cell identity. Additionally, we provide a panel of epigenetic markers for the efficient and safe generation of ES- and induced pluripotent stem cell (iPS)-derived myogenic progenitors for therapeutic applications.
\end{abstract}

Keywords: DNA methylation, Cellular identity, Myogenesis, Pax7-induced ESCs, Apobec2, Epimarkers

\section{Background}

Developmental signals induce changes in gene expression and chromatin structure in order to define cell identity. Epigenetic mechanisms, and DNA methylation in particular, are essential for mammalian development being involved in the establishment and maintenance of cellular identity by creating cellular memory during embryonic development [1-3]. DNA methylation controls $\mathrm{X}$-chromosome inactivation, expression of imprinted genes, represses the transcription of repeated sequences and prevents relocation of transposable elements (reviewed in [4]). In addition, DNA methylation affects gene expression by regulating promoters and distal regulatory elements, such as enhancers and insulators (reviewed in [5]).

\footnotetext{
* Correspondence: msuelves@imppc.org

${ }^{1}$ Institut de Medicina Predictiva i Personalizada del Càncer (IMPPC) and

Institut Germans Trias i Pujol (IGTP), Campus Can Ruti, 08916 Badalona, Spain Full list of author information is available at the end of the article
}

In the last few years, global analyses of DNA methylation dynamics in pluripotent stem cells and their differentiated progeny have begun to uncover the mechanisms involving coordinated changes occurring in the epigenome that are essential for lineage-specification and maintenance of cellular identity [6-15]. Very recently, we reported the genome-wide comparison of the DNA methylation profiles of pluripotent embryonic stem cells and muscle stem cells showing, in agreement with other studies, that cellular differentiation is associated with a modest but global increase in DNA methylation, which interestingly is accompanied by lineage-specific demethylation [16]. Although the mechanisms controlling DNA demethylation are still not well defined, several studies suggest the involvement of two major pathways in this process: the activity of TET methylcytosine dioxygenase proteins $[17,18]$ and AID/APOBEC cytidine deaminase enzymes [19-21]. Importantly, active DNA demethylation 
was reported in human muscle-specific genes in heterokaryons derived from the fusion of human non-muscle cells with mouse muscle cells, indicating a dynamic DNA methylation/demethylation interplay during muscle differentiation [22].

Skeletal muscle is the tissue accounting for the largest percentage of body mass and contributes to multiple body functions including the voluntary movements. The skeletal muscle is mainly composed of highly specialized and terminally differentiated multinuclear, post mitotic and contractile myofibres, and a small pool of muscle stem cells, known as satellite cells (SCs), which are essential for the growth, maintenance and regeneration of skeletal muscle throughout life (reviewed in [23]. The transcriptional regulatory network controlling the establishment of muscle embryonic progenitors in the myotome, as well as the activation of the satellite cells in the adult, involves upregulation of myogenic regulatory factors or MRFs (Myf5, MyoD, Mrf4 and Myog), as well as silencing of other lineage-specifying genes (reviewed in [24]). In addition, members of the Pax gene family $P a x 3$ and $P a x 7$ lie upstream of MRFs and their expression is crucial to regulate muscle progenitor cell functions [25, 26]. Pax7 is essential for the formation and maintenance of SCs, being expressed in quiescent and activated SCs, as well as in proliferating myogenic progenitors [27].

In the present study, we addressed for the first time the DNA methylation dynamics of the major genes orchestrating myogenic determination and differentiation by comparing pluripotent ESCs, myogenic precursors from Pax7-inducible ESCs, proliferating muscle stem cells, and their respective myotube derivatives. Our results showed a common muscle-specific DNA demethylation signature required to acquire and maintain the muscle-cell identity. Notably, downregulation of the muscle-specific cytidine deaminase Apobec 2 in ES-derived myogenic precursors reduced myogeninassociated DNA demethylation and dramatically affected the expression of differentiation markers and, ultimately, muscle differentiation.

\section{Results}

DNA methylation profile of myogenic genes harbouring CpG island-promoters during myogenic differentiation

To elucidate DNA methylation dynamics associated with skeletal myogenic lineage commitment and terminal differentiation, we focused the analysis on genes known to be associated with this process: developmental genes (Pax3 and Pax7), myogenic regulatory factors (MyoD, Myog and Mrf4) and terminal differentiation genes (Myh1, Myh4, Myh8 and Ckm). Interestingly, these genes could also be classified according to their CpG distribution, which represent sites of potential DNA methylation.
Pax3, Pax7 and MyoD contain CpG islands (CGIs) in their promoters, belonging to the $\mathrm{CpG}$-rich genes category; meanwhile, the other genes do not have CGI and their promoters are considered CpG-poor. Using bisulphite sequencing analysis, we compared the DNA methylation state of undifferentiated ESCs and muscle stem cells, isolated from adult skeletal muscle tissue, along with respective differentiated myotubes and mature myofibres (Fig. 1a). In addition, to assess whether the DNA methylation events were muscle-lineage specific, we analysed the methylation profiles of the following nonmyogenic cell lines: neuronal precursor cells (NPCs), mouse embryonic fibroblasts (MEFs) and cardiomyocytes (HL1). As shown in Additional file 1a, b, all analysed CGIs in Pax3 and Pax7 regulatory regions were completely unmethylated in all the samples. Similar results were previously reported for MyoD CGI [28]. These results were expected since CGIs, usually located in the promoter regions of housekeeping and developmental genes, are known to be largely resistant to DNA methylation [29-31].

Since DNA methylation often occurs in non-CGI regions, we investigated whether enhancers and promoters present a cell-specific deposition of this modification. Previous studies of other groups identified two musclespecific regulatory regions upstream of the MyoD transcription start site (TSS), located at $-20 \mathrm{~kb}$ and $-5 \mathrm{~kb}$, respectively [32-34]. Importantly, it was shown that the distal $M y o D$ enhancer located at $-20 \mathrm{~kb}$ of the TSS was modulated by DNA methylation in mouse tissues [31]. Therefore, we analysed the methylation status of $\mathrm{Pax} 3$ hypaxial somatic enhancer [35] located at $-8 \mathrm{~kb}$ of the Pax3 TSS, the Pax7 region containing the critical RBPJk binding site [36] located at $-7,4 \mathrm{~kb}$ of Pax7 TSS, and the two MyoD enhancer regions. As shown in Fig. 1b, although these regulatory regions were totally or partially methylated in ESCs and in non-muscle cells, $P a x 3$ and $-20 \mathrm{~kb} M y o D$ enhancers were almost completely free of methylation in myogenic cells, which correlates with gene expression (Fig. 1b). On the contrary, the Pax7 and $-5 \mathrm{~kb}$ distal regulatory region of $M y o D$ were both found highly methylated in muscle cells (Fig. 1b and Additional file 1c), suggesting that their activation would be independent of DNA methylation. Notably, NPCs and HL1 cells presented high levels of Pax3 expression, despite high DNA methylation levels. This result would suggest that the Pax3 hypaxial enhancer might be mainly associated to enhance Pax3 expression in committed skeletal myogenic cells.

Next, to further characterize the epigenetic landscape involved in myogenic regulation, we took advantage of publicly available ChIP-seq data of histone post-translational modifications [37, 38]. As schematized in Fig. 1c, Pax3, Pax7 and MyoD promoters 


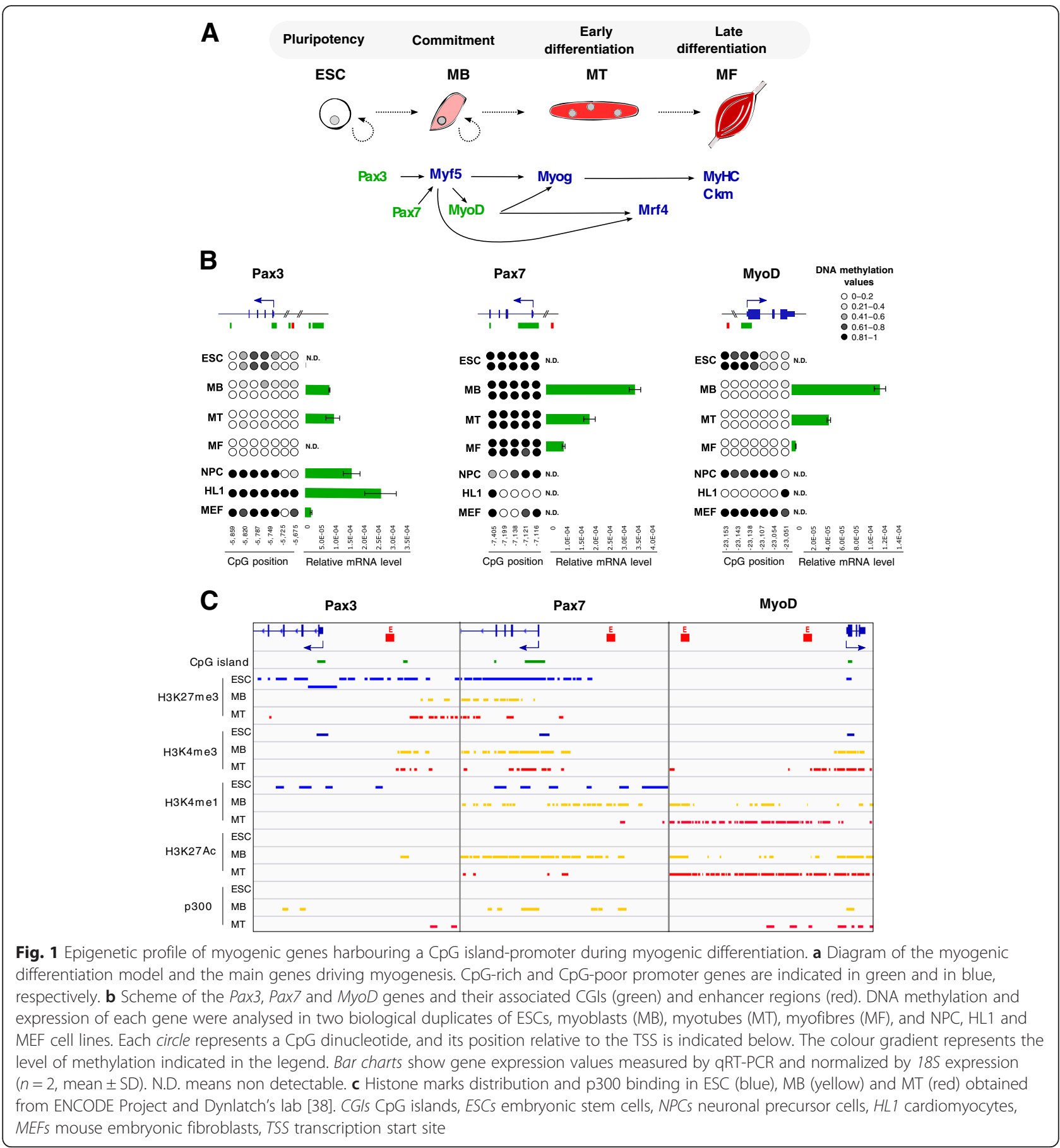

showed a bivalent chromatin state characterized by histone 3 trimethylated on lysine 4 (H3K4me3) and lysine 27 (H3K27me3) in ESCs, which has been associated to poised transcription [39, 40]. This bivalent state was clearly resolved in favour of the positive mark H3K4me3 at myoblast (MB) and myotube (MT) stages for $M y o D$, whereas the developmental genes Pax3 and Pax7 retained the bivalent state (Fig. 1c).
The analysis of these loci, including enhancer and distal regions, showed a gain in deposition of histone 3 monomethyl-lysine4 (H3K4me1), acetyl-lysine 27 (H3K27Ac) and increased recruitment of the p300 acetyltransferase at MB stage, and also at MTs in the case of $M y o D$. Since $M y o D$ is already higher expressed in MBs, this maintenance of active enhancer marks in MTs might be involved in keeping an open chromatin 
state of the region to maintain gene expression, rather than promoting further transcriptional activation. All together, these results indicate that the unmethylated state of CGIs is conserved across the different cell types, whereas $\operatorname{Pax} 3$ and -20 kb MyoD enhancer element show cell type-specific dynamic methylation patterns associated with changes in gene expression.

\section{Myogenic-specific promoters undergo DNA}

\section{demethylation during muscle-lineage specification}

Unlike MyoD, all the other MRFs Myf5, Mrf4 and Myog, as well as the muscle differentiation markers display low CpG content promoters. The analysis of the promoter region, containing E-box and Mef2 binding sites, of Myog and the other differentiation genes Ckm, Myh1,
Myh4 and Myh8 revealed high levels of methylation in ESCs and non-muscle cells, correlating with gene silencing, whereas the promoter regions in muscle cells were unmethylated (Fig. 2a). Interestingly, these differentiation genes became demethylated at the $\mathrm{MB}$ stage but remained silenced. These myogenic genes were not bivalent at the ESC stage and only presented active chromatin marks (H3K4me3 and H3K27Ac) in the promoter regions according to their expression timing. Strikingly, the terminal differentiation genes Myh1, Myh4 and Myh8 gained the repressive mark H3K27me3 in MB cells after DNA demethylation, suggesting that gene expression was maintained epigenetically repressed by PRC2 complex until the onset of the terminal differentiation stage (Fig. 2b). Interestingly, Mrf4 followed
A

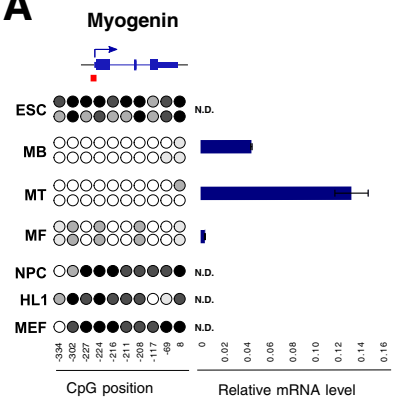

Myh1

$+$

ESC ::::

MB 0000

MT 8000

MF 8088

HL1 $000 \times$ N.D.

MEF $\bullet \bullet \bullet \bullet$ N.D.

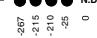

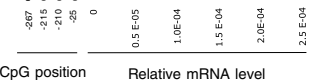

Mrt4

ESC :::::8::

мв :::::::: ।

мт :::::::: $\mathbf{E -}$

MF 80808088

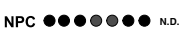

HL1 $\bullet \bullet \bullet \bullet \bullet \bullet$ N.D.

MEF $\bullet \bullet \bullet \circ \bullet \bullet \bullet$ N.D.

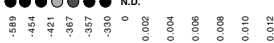

CpG position Relative mRNA level

Myh4

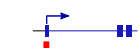

ESC ::::8: no

MB 800808 no

мт 800080 м.

MF 888880

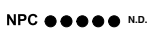

HL1 ०००००

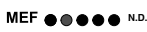

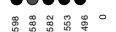

$\bar{l}$
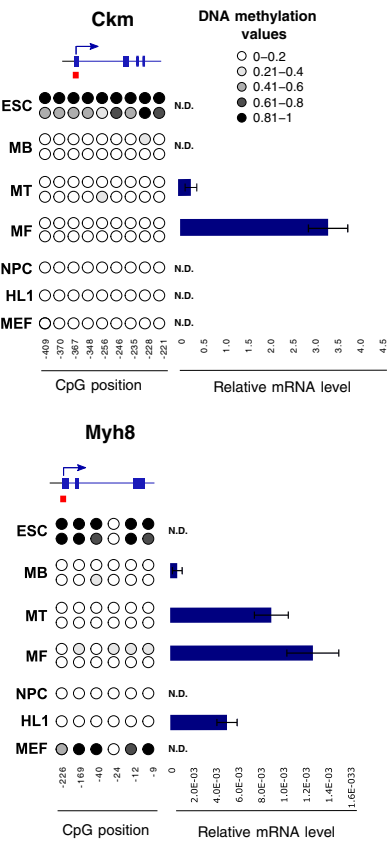

B Myogenin Myf6

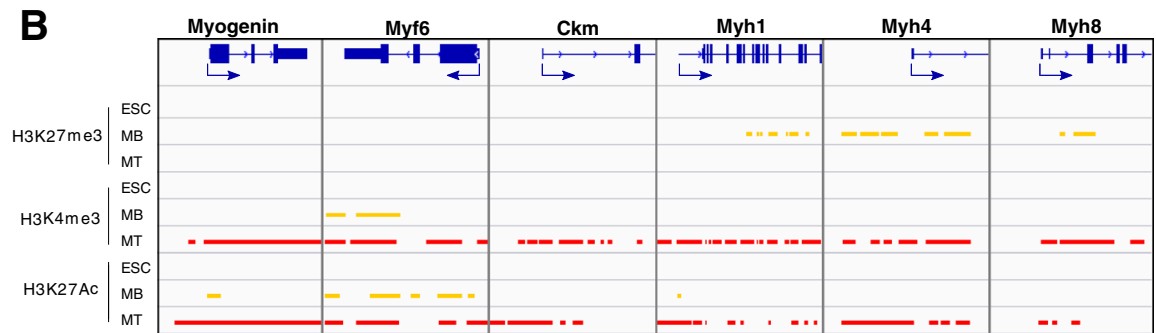

Fig. 2 Epigenetic profile of muscle-specific CpG-poor promoter genes during myogenesis. a Scheme of the Myog, Mrf4, Ckm and Myh1, 4 and 8 loci. Regions analysed by sodium bisulphite sequencing are indicated in red. Two biological replicates were performed for ESCs, myoblasts (MB), myotubes (MT) and myofibres (MF) and in NPC, HL1 and MEF cell lines. Each circle represents a CpG dinucleotide and its position relative to the TSS is indicated below. The colour gradient represents the level of methylation indicated in the legend. Bar charts show gene expression values measured by qRT-PCR and normalized by 185 expression ( $n=2$, mean \pm SD). N.D. means non detectable. $\mathbf{b}$ Histone marks distribution and p300 binding in ESC (blue), MB (yellow) and MT (red) obtained from ENCODE Project and Dynlatch's lab [38]. ESCs embryonic stem cells, NPCs neuronal precursor cells, HL1 cardiomyocytes, MEFs mouse embryonic fibroblasts, TSS transcription start site 
a different DNA methylation pattern, being highly demethylated only in mature myofibres, where it is specifically highly expressed (Fig. 2a).

We also investigated the epigenetic profile of highly expressed pluripotency genes in ESC that become silenced in MB and MT. Genes containing a CGI overlapping their promoter region, such as Sox2 and Fgf4, were totally unmethylated in all cell types, whereas genes with CpG-poor content promoters, such as Dppa4 and Pou5f1, became highly hypermethylated upon cellular differentiation (Additional file 2a, b). Regarding histone marks, ESC showed high levels of H3K4me3 in the promoter regions of Sox2 and Fgf4, whereas MB and MT cells gained H3K27me3 in association with gene silencing (Additional file 2c). Dppa4 and Pou $5 f 1$ promoters presented also the active marks H3K4me3 and H3K27Ac. However, in differentiating cells the H3K27me3 mark was not acquired (Dppa4) or in a very small extent (Pou5f1), leaving the gain of DNA methylation as the postulated epigenetic silencing mechanism (Additional file 2c).

All together, these results suggest that myogenic differentiation genes become demethylated at CpG-poor regulatory regions during muscle-lineage determination, and are maintained silenced by the polycomb repressive histone mark H3K27me3 until gene activation. In contrast, pluripotency gene silencing involves complete DNA methylation or gain of H3K27me3 mark, depending on promoter $\mathrm{CpG}$ context.

\section{Pax7-induced ES-derived muscle differentiation recapitulates myogenic DNA methylation changes}

In order to recapitulate the commitment of myogenic precursors during embryonic development, we utilized mouse ES cells engineered to express $\operatorname{Pax} 7$ under the control of a doxycycline-inducible promoter (iPax7) [41]. At day 3 of embryoid body (EB) differentiation Pax7 transgene expression was induced by doxycycline (Dox), and at day 5 of EB differentiation the mesodermal precursor cells (PDGFR $\alpha^{+} / \mathrm{FLK} 1^{-}$) were sorted, with or without Dox, and grown for 5 more days (Fig. 3a). Importantly, only the iPax7-ES-derived myogenic precursors treated with Dox expressed myogenic differentiation markers such as Myogenin, Ckm and Myh8 and generated myotubes upon differentiation (Fig. $3 \mathrm{~b}$ and Additional file 3). To assess to what extent the iPax7ES-derived myogenic progenitors were epigenetically reprogrammed, we evaluated the DNA methylation state of the main myogenic genes in three independent time courses. As expected, preliminary analysis revealed the complete unmethylated state of the CGI located at the $P a x 3$ and $M y o D$ promoter regions during the differentiation process (data not shown). Importantly, the CpG-poor myogenic regulatory regions also showed a very similar DNA methylation signature compared to primary muscle stem cells and, interestingly, a stepwise DNA demethylation was identified (Fig. 3c). The Pax3 hypaxial enhancer became completely demethylated at day 3 of EB formation, independently of $\operatorname{Pax} 7$ induction and despite the lack of Pax3 expression at any stage of differentiation (Fig. 3b, c). Contrarily, the $-20 \mathrm{~kb}$ enhancer of $M y o D$, the $-111 \mathrm{~kb}$ enhancer of Myf5 (where Pax7 is bound) and Myf5 promoter became partially demethylated at a later time and exclusively in Pax7-induced myogenic precursors, coinciding with the increase in mRNA expression. Notably, at day 17 (iPax7-MTs) the demethylated state persisted, despite the dramatic reduction of $M y o D$ and Myf5 expression levels (Fig. 3b, c). Myogenin promoter showed a similar demethylation time course, reaching a total loss of DNA methylation at the iPax7MB-precursor stage when Myogenin was slightly expressed, and maintained in iPax7-MTs, when the Myogenin gene showed the maximum expression level (Fig. 3b, c). Interestingly, the promoters of the late differentiation genes $M y h 8$ and $C \mathrm{~km}$ remained fully methylated until the iPax7-MT stage, when they became partially demethylated simultaneously with gene activation (Fig. 3b, c). Importantly, we did not observe any loss of DNA methylation in the absence of Pax7 expression in the control cells (no Dox treatment), indicating that the observed demethylation was skeletal musclespecific. Finally, the analysis of the promoter regions of the pluripotency genes Pouff1 and Dppa4, which are progressively silenced, showed a similar gain of DNA methylation during cell differentiation as observed in primary myoblasts (Fig. 3b, c).

\section{Impaired myogenic differentiation in Apobec2 knockdown myogenic precursors is associated with reduced DNA demethylation}

DNA demethylation at specific myogenic regulatory regions was clearly observed in primary myoblasts and in iPax7 ESC-derived myogenic precursors (Figs. 1b, 2a and 3c). At first, we questioned whether the reported demethylation could result from a passive loss of methylation, in which the lack or the significant reduction of DNA methyltransferases (Dnmts) coupled to the successive cell divisions would lead to the loss of this epigenetic mark. We analysed the expression levels of the Dnmt1 responsible for the maintenance of the existent DNA methylation pattern, and Dnmt3a and Dnmt3b, which add de novo methyl groups after DNA replication. All Dnmts were expressed, and, as shown in Additional file 4, the expression levels of Dnmt1 and Dnmt3a did not significantly change during EB differentiation, while Dnmt3b expression decreased during cell differentiation independently of Pax7 expression. These observations 

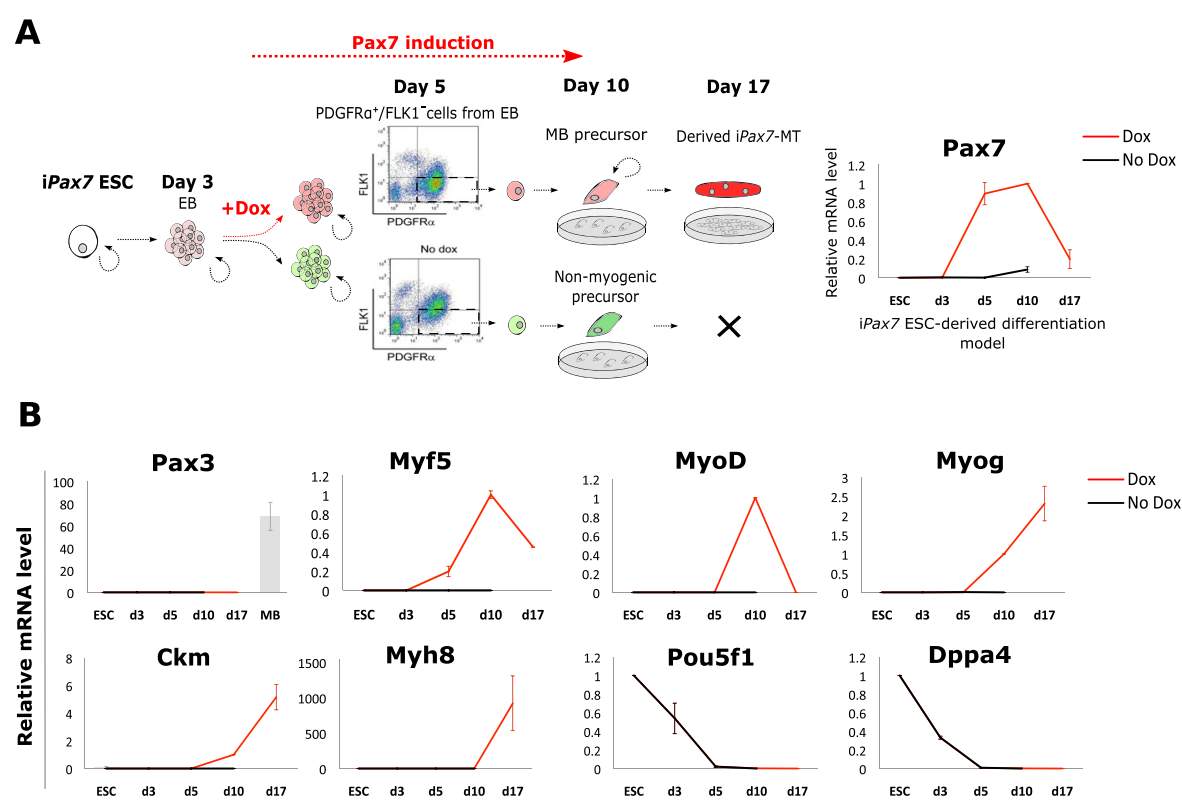

iPax7 ESC-derived differentiation model

C

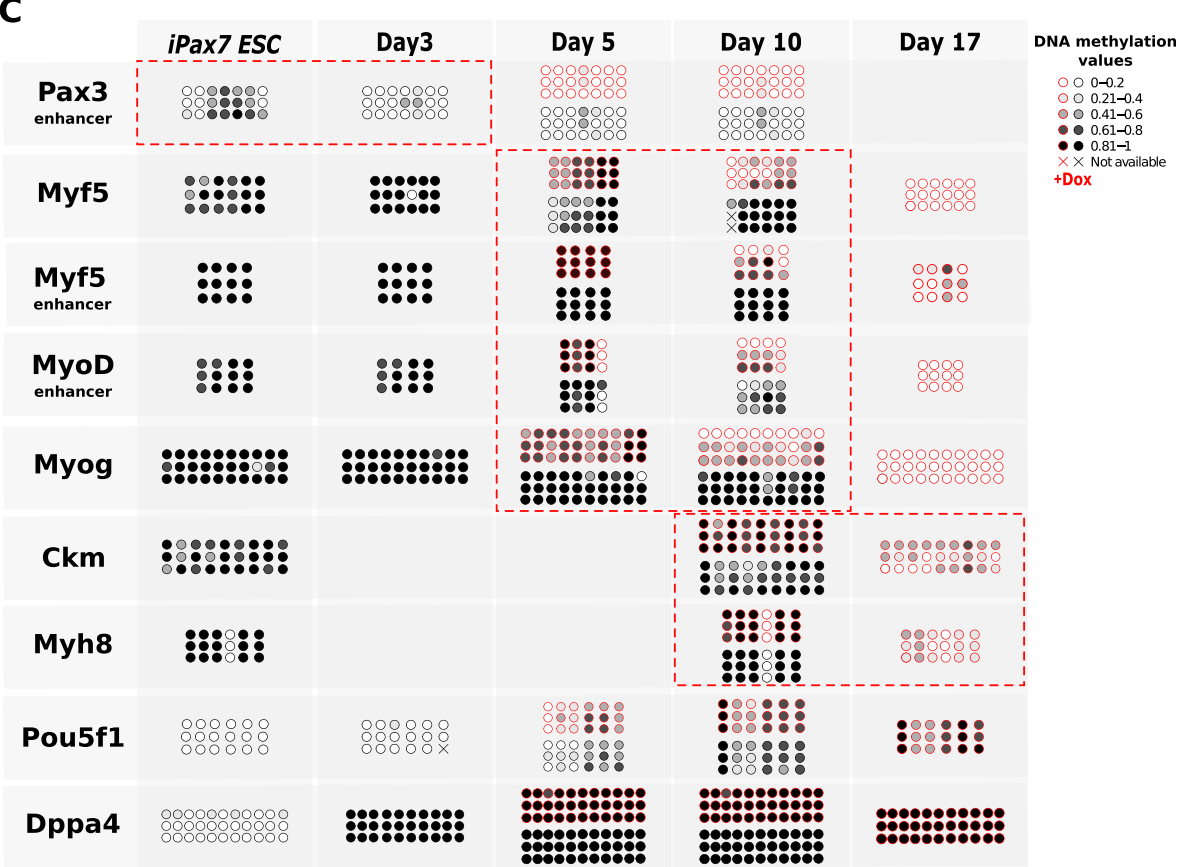

Fig. 3 Pax7-engineered ESCs efficiently acquired the myogenic DNA methylation profile. a Experimental scheme of the differentiation protocol to generate ES-derived myogenic progenitors using iPax7 mES cells (left). Pax7 induction assessed by qRT-PCR (right). $\mathbf{b}$ Expression profiles of markers of pluripotency (Pou5f1 and Dppa4), muscle lineage commitment (Pax3, Myf5 and MyoD) and muscle differentiation (Myog, Ckm and Myh8) were measured by qRT-PCR at the successive time points of Pax7 ESC-derived myogenic model and normalized by Gapdh expression $(n=3$, mean \pm SD). c DNA methylation dynamics of Pax3, Myf5 and MyoD enhancers and CpG-poor promoters of muscle-specific genes (Myf5 Myog, Ckm and Myh8) and pluripotency genes (Pou5f1 and Dppa4) during Pax7-induced myogenesis (+Dox shown in red and -Dox shown in black). The results of three biological replicates are shown. Each circle represents a CpG dinucleotide and the colour gradient represents the level of methylation indicated in the legend and assessed by sodium bisulphite sequencing. Demethylation waves occurring during the Pax7-induced myogenesis are denoted by red dotted boxes. ESCs embryonic stem cells, Dox doxycycline; iPax7 inducible Pax7 
would suggest that specific DNA methylation reduction on muscle-related genes might be mediated by an active mechanism rather than by a passive one.

The two major pathways involved in controlling the DNA demethylation process are the oxidation-mediated demethylation by TET proteins and the cytosine deamination by AID/APOBEC cytidine deaminase enzymes. The expression levels of Tet 1 , Tet 2 and Tet 3 did not change in the presence or absence of $\operatorname{Pax} 7$ expression during the EB differentiation, as shown in Additional file 4b. However, the expression levels of Apobec2, the skeletal muscle specific member of the AID/APOBEC family, were highly induced upon Pax7-mediated muscle-commitment, being very high at the progenitor stage and derived MTs (Fig. 4a). Importantly, despite the lack of high specificity of the Apobec2 antibody (Additional file 4c) a clear increase of Apobec 2 protein was observed by western-blot concomitant with the differentiation progression (Fig. 4a).

In order to test whether Apobec2 is required for the myogenic process, we performed loss of function experiments by down-regulating Apobec2 levels using lentiviral vectors encoding for specific shRNAs. To identify the most appropriate time point for shRNA viral-mediated transduction (before DNA demethylation has taken place) we performed and analysed a daily time course starting from Dox-treated PDGFR $\alpha^{+} / \mathrm{FLK}^{-}$sorted cells from day 5 EBs until iPax7-MB precursor stage (day 10). As shown in Fig. 4b, we observed a perfect correlation between gradual DNA demethylation of the Myogenin locus and increased gene expression, which starts at EB day 9. Based on these data, we decided to transduce Doxtreated PDGFR $\alpha^{+} / \mathrm{FLK}^{-}$cells at day 6 of differentiation using two different Apobec2 shRNAs (shRNA1 and shRNA4). As expected, four days after transduction, Apobec2 shRNAs dramatically knocked-down Apobec2 mRNA and protein levels (Fig. 4c) without affecting Pax7 expression (data not shown). Importantly, Apobec2 knockdown was associated with a severe downregulation of Myogenin expression, both at mRNA and protein level and, ultimately, impairment of terminal muscle differentiation (Fig. 4d). Interestingly, the methylation analysis of the Myogenin promoter upon Apobec2 knockdown showed a significant methylation gain in $70 \%$ of the promoter CpGs (Kruskal-Wallis test, $p$-value $<0.05)$ compared to the control cells (Fig. 4e). Finally, we also analysed the impact of Apobec 2 knockdown in $M y o D$ and $M y f 5$ DNA methylation levels, and, as shown in Additional file 5a,b, although we observed a small increase of methylation in some of the $\mathrm{CpGs}$, it was not statistically significant. All these results together, suggest that Apobec 2 might participate more actively in the DNA demethylation process required to drive myogenic differentiation rather than in regulating the DNA methylation-dependent myogenic commitment.

\section{Discussion}

Tissue-specific stem cells are lineage-restricted cells that have lost pluripotency capacities and gained cell-type identity. Epigenetic regulation, including DNA methylation and the post-translational modifications of histones, is crucial in the establishment and maintenance of cellular identity $[1-3,42]$. In this study, we analysed for the first time the DNA methylation dynamics of the principal genes orchestrating myogenic determination and differentiation programs by comparing ES cells and their Pax7-induced skeletal myogenic derivatives with muscle stem cells, both in proliferating and differentiating conditions. The detailed analysis of CpG-poor regulatory regions for the developmental gene Pax3, MyoD and Myogenin genes as muscle cell-identity transcription factors, and Ckm, Mhy1, Myh4 and Myh8 as myogenic terminal differentiation genes revealed a specific DNA demethylation signature required to acquire and maintain muscle-cell identity during the establishment of the muscle lineage (Figs. 1b, 2a and 3c). These results reinforce observations reported in other cellular models that lineage-specific DNA demethylation, together with pluripotency genes hypermethylation, occur during early cell fate decisions conferring unique DNA methylation patterns which correlate with defined cellular identities [43-46]. Interestingly, our results showed that the crucial myogenic differentiation factor Myogenin became fully demethylated in muscle-committed cells before gene expression (Fig. 2a). However, these results were in disagreement with previous work performed in $\mathrm{C} 2 \mathrm{C} 12$ cells where loss of methylation was observed between myoblasts and myotubes [47, 48]. To address this controversy, we isolated freshly satellite cells from adult mice, and, interestingly, the DNA methylation analysis of the Myogenin promoter revealed the complete demethylation of the promoter in ex vivo isolated muscle stem cells (unpublished data). These results would indicate that DNA demethylation of Myogenin promoter occurs during muscle-lineage determination, allowing the acquisition of a transcriptional poised state before gene expression during muscle differentiation. Notably, gene silencing of terminal differentiation Myosin genes in proliferating myoblasts upon DNA demethylation is maintained by the acquisition of the Polycomb repressive mark H3K27me3 (Fig. 2b), as previously reported for Myog and Ckm promoters [49, 50]. During terminal differentiation, H3K27me3 is replaced by the positive marks H3K4me3 and H3K27Ac, which result in gene transcription. This two-step repressive mechanism, where DNA methylation is replaced by $\mathrm{H} 3 \mathrm{~K} 27 \mathrm{me} 3$, is 


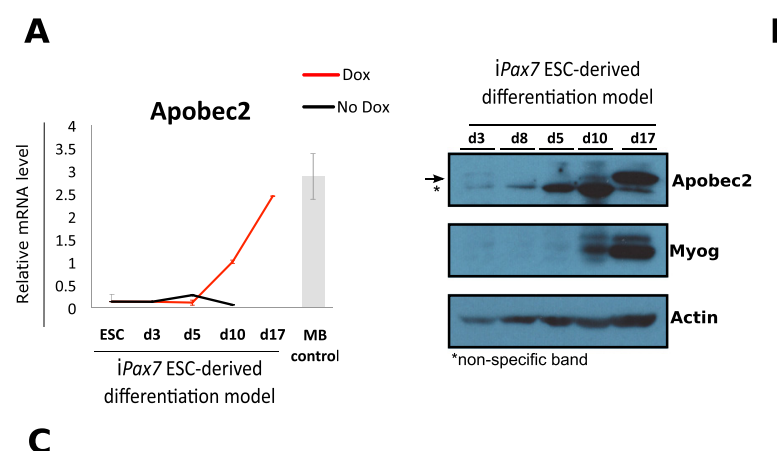

B
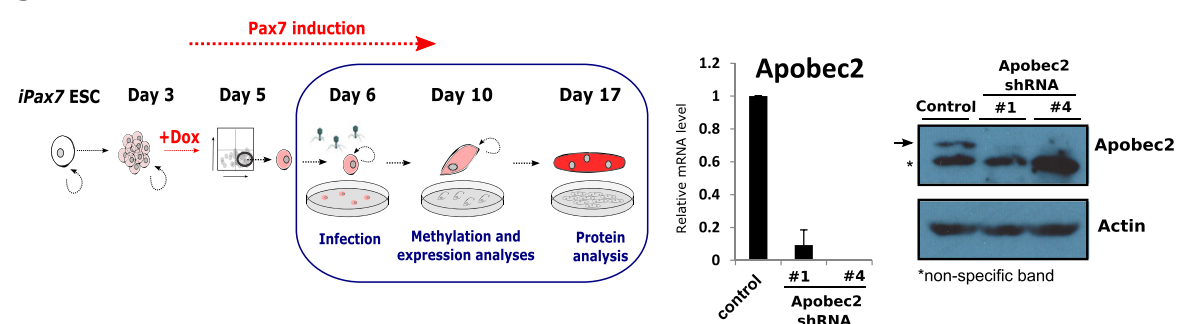

D

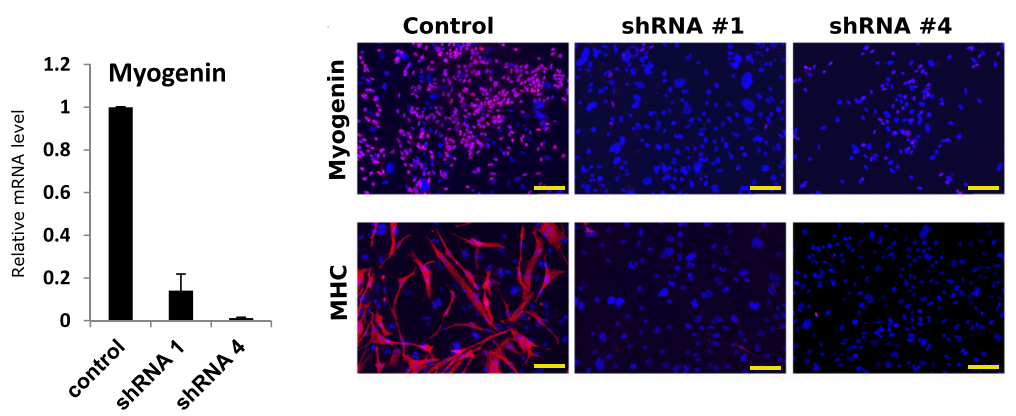

$\mathbf{E}$

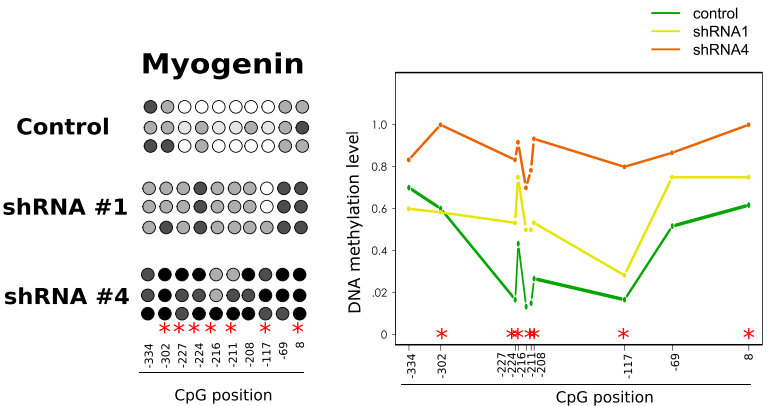

Fig. 4 Impaired myogenic progression and differentiation and reduced DNA demethylation in Apobec2 knockdown myogenic precursors. a Time course of Apobec2 expression during differentiation of P Pax7 ES cells in presence or absence of Pax7, which was induced by adding doxycycline (Dox) to the culture media. Apobec2 expression was measured by qRT-PCR (left), and by western blotting (WB) (right). Apobec2 mRNA expression was normalized by Gapdh expression ( $n=3$, mean $\pm \mathrm{SD}$ ) and as a reference the expression level in primary myoblasts (MB control) was measured ( $n=2$, mean \pm SD). Myog and actin WB were used as controls for myogenic differentiation and equal loading, respectively. $\mathbf{b}$ DNA methylation and gene expression analyses of Myogenin were performed in a daily time course after Dox induction in the inducible myogenic model $(n=2)$. Each circle represents a CpG dinucleotide and its distance to the gene TSS is indicated below. The colour gradient represents the methylation level indicated in the legend. N.D. means non detectable. c Scheme of the experimental approach followed to knockdown Apobec2 in the inducible Pax7 model (left). Gene expression and protein level to evaluate Apobec2 knockdown efficiency using two independent clones were compared to control vector (right) ( $n=3$, mean \pm SD; representative Apobec2 WB with the corresponding actin loading control). $\mathbf{d}$ Myogenin expression was measured in Pax7-induced myogenic precursors infected with Apobec2 shRNAs 4 days upon lentiviral transduction (right) $(n=3$, mean \pm SD). Representative images of Pax7-induced myogenic precursors infected with Apobec2 shRNAs under differentiation conditions stained with Myogenin and MHC antibodies. Scale bar: $100 \mu \mathrm{m}$. e DNA methylation analysis by sodium bisulphite sequencing of the Myogenin promoter in Pax7 ES-derived myogenic precursors transduced with Apobec2 shRNA1 and shRNA4 in three biological replicates. Each circle represents a CpG dinucleotide and its distance to the gene TSS is indicated below. The colour gradient represents the level of methylation indicated in the legend. Statistical significance with respect to the control samples is indicated with * for $p$-value $<0.05$ applying the Kruskal-Wallis test. ESC embryonic stem cell, TSS transcription start site, shRNA short hairpin RNA 
also observed when ESCs are induced to differentiate [51] and represents a switch from a stable repression mediated by DNA methylation to a more facultative repression mediated by the histone code [4].

Mrf4 is considered a determination and differentiation myogenic gene and is the only MRF expressed in mature myofibres [52, 53]. Curiously, Mrf4 promoter is the only one still repressed by DNA methylation in undifferentiated myoblasts, being highly demethylated only in mature myofibres where it is highly expressed (Fig. 2a). A recent paper demonstrated that adult satellite cells emerged from embryonic founder cells in which the Mrf4 gene was activated [54], but intriguingly, our results showed that Mrf4 promoter was completely methylated in all cell types analysed except in mature myofibres. Very recently we demonstrated that the multiple enhancers regulating the complex spatial-temporal expression of the Myf5/Mrf4 locus during embryogenesis were specifically demethylated in muscle-committed cells [16]. In that context, we speculate that complete demethylation of Mrf4 promoter would be only required in mature myofibres to fully activate and maintain its high expression levels.

It is well known that Pax7 has a key role in the formation and maintenance of muscle committed progenitors. The engineered iPax7-ESC model let us recapitulate the commitment of myogenic precursors during embryonic development and revealed the acquisition of a very similar DNA methylation signature, compared to primary muscle cells (Fig. 3c). Importantly, these results support the use of iPax7 ES-derived myogenic progenitors as a bona fide model to generate in vitro myogenic precursors with therapeutic purposes. The detailed analysis of this stepwise model showed that the myogenic differentiation process occurred coupled to a gradual loss of DNA methylation in myogenic regulatory regions in consecutive waves. Initially, $P a x 3$ enhancer became demethylated before $\operatorname{Pax} 7$ induction in line with its expression pattern, which is not restricted to the myogenic lineage [55]. Next, Myf5, MyoD and Myogenin CpG-poor regulatory regions became demethylated in iPax7-myoblast precursors correlating with transcriptional activation (Fig. 3b-c). Finally, the terminal differentiation myogenic genes Ckm and Myhs became simultaneously demethylated and activated during late differentiation, when iPax7 myogenic precursors differentiated and fused forming myotubes. This late demethylation wave only occurred in ES-derived differentiating myocytes and not in primary myotubes, already demethylated in the $\mathrm{MB}$ stage. This observation points out an epigenetically accentuated myogenic commitment of adult muscle stem cells compared to myogenic precursors. Importantly, the loss of DNA methylation only took place upon $\operatorname{Pax} 7$ expression (+Dox) indicating that Pax7 is required for skeletal muscle-specific demethylation. Notably, the differentially methylated enhancer located at $-111 \mathrm{~kb}$ of Myf5 TSS is a direct target of Pax7 in satellite cells [56], suggesting a link between Pax7 and DNA methylation. In the last years, several studies have shown the crosstalk between muscle transcription factors and chromatin modifiers. In this regard Pax7 has been shown to recruit the Wdr5-Ash2L-MLL2 histone methyltransferase complex to target genes, in order to stimulate myogenic transcription [57]. In the same line, MyoD interacts with the chromatin remodelling complex SWI/SNF [58, 59], and recruits the histone acetyltransferase P300 and the histone methyltransferase Ash2L to activate muscle genes [60-62]. In that context and taking into account our results we propose a model (Fig. 5) where DNA methylation prevents inappropriate expression of muscle genes in ESCs, being removed during the commitment to the skeletal muscle lineage. The expression of myogenic transcription factors might modulate both the recruitment, direct or indirect, of DNA demethylases to reduce DNA methylation and chromatin compaction, and histone modifiers/chromatin remodelers to activate transcription of muscle genes. In proliferating myoblasts, the differentiation genes would be kept in a silenced/ poised transcriptional state by PRC2 and HDACs complexes, whereas in myotubes they would be expressed upon the recruitment of chromatin activating complexes.

To investigate the possible pathway involved in DNA demethylation during myogenesis we focused on Apobec2 (Apolipoprotein B mRNA editing enzyme catalytic polypeptide 2), a member of the cytidine deaminase family expressed exclusively in cardiac and skeletal muscle tissues with unknown functions [63, 64]. The generation of Apobec $2^{-1-}$ mice showed no major defects in mouse health, fertility or survival up to 1 year of age [65]. However, detailed analysis of these animals revealed a 15-20\% reduction in body mass from birth onwards, a clear histological evidence of a mild myopathy during aging, and a markedly increased ratio of slow to fast fibres in soleus Apobec $^{-1-}$ muscles [66]. Although the cytidine deaminase activity of Apobec2 is still controversial [64, 67-69], it has been reported that during zebrafish development Apobec2b stimulates DNA demethylation [70], and AID/Apobec proteins promote demethylation of $5 \mathrm{hmCs}$ in mammals [21]. Our results showed that Apobec 2 expression was highly induced upon musclecommitment in iPax7-myogenic precursors (Fig. 4a) and, importantly, the downregulation of Apobec2 dramatically impaired muscle differentiation, abolishing myogenin and myosins expression (Fig. 4d), in agreement with experiments performed on $\mathrm{C} 2 \mathrm{C} 12$ myoblast cells showing that Apobec2 was required for myotube formation [71]. Recently, Powell and co-workers reported that Apobec2 had an essential role during retina and optic nerve 


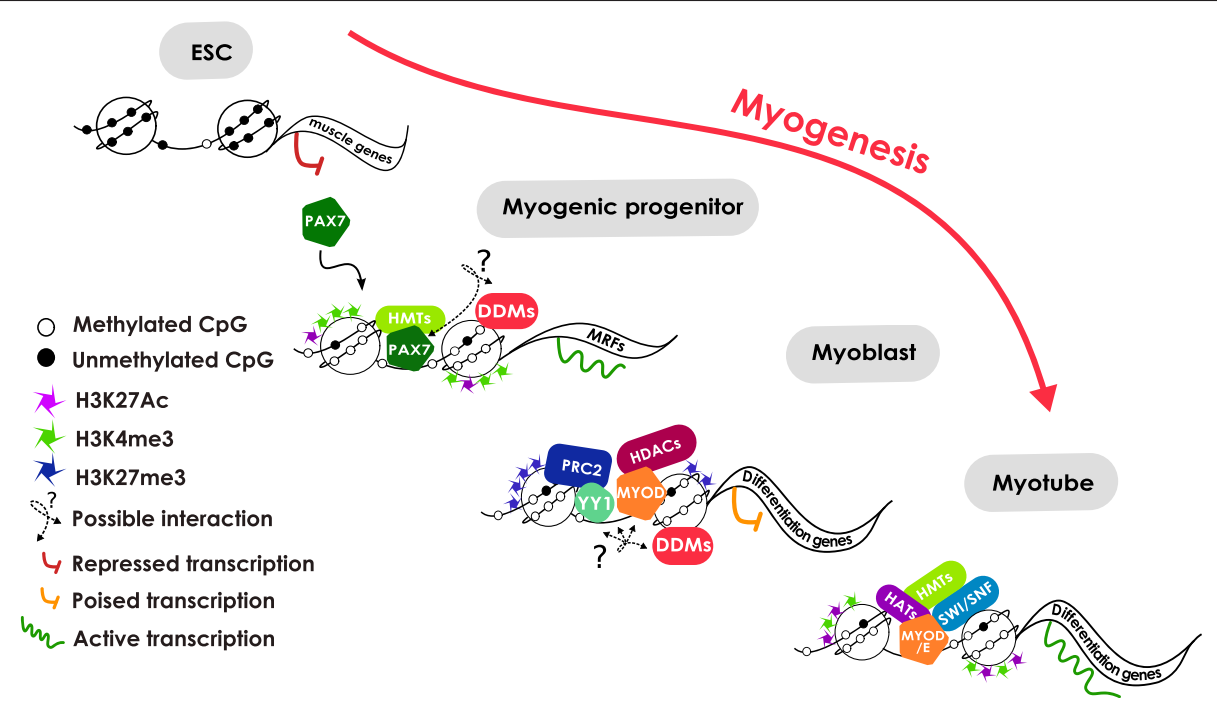

Fig. 5 Model for the epigenetic control of muscle-specific gene expression during myogenesis. Diagram proposing a simplified model where myogenic transcription factors would activate muscle genes by modulating both the recruitment, direct or indirect, of DNA demethylases to reduce DNA methylation levels and chromatin compaction, and histone modifiers/chromatin remodelers to activate transcription of muscle genes. In proliferating myoblasts, the differentiation genes would be kept in a silenced/poised transcriptional state by PRC2 and HDACs complexes, whereas in myotubes they would be expressed upon the recruitment of chromatin activating complexes. Abbreviations: DDMs DNA demethylases, HATs histone acetyltransferases, HDACs histone deacetylases, HMTs histone methyltransferases, PRC2 Polycomb repressive complex 2, SWI/SNF SWI/SNF ATP-dependent chromatin remodelling complex, YY1 Yin and Yang 1

regeneration [72], although the small changes observed in DNA methylation during tissue-regeneration were independent of Apobec2 expression [73]. Interestingly, our results showed that Myogenin DNA methylation levels were significantly higher in iPax7-myoblast precursors when Apobec 2 activity was abolished, correlating with gene silencing (Fig. 4e). However, the $M y o D$ and $M y f 5$ DNA methylation changes observed upon Apobec2 knockdown were smaller, and not statistically significant. That could be due to the existence of some cell heterogeneity during the process of Pax7-dependent myogenic induction, which could mask the demethylation events occurring in $M y o D$ and Myf5 genes. Another explanation could be related to the fact that MyoD and Myf5 play a very early role in muscle-lineage determination, as mouse embryos with targeted mutation in both genes lack myoblasts and differentiated skeletal muscles [74]. Therefore, we cannot rule out the involvement of other mechanisms, such us Tetmediated DNA demethylation, in the epigenetic activation of these two early-induced genes. Altogether, our results suggest that Apobec2 might participate in the active DNA demethylation process required to drive myogenic differentiation. Apobec 2 has emerged as an important myogenic regulator that would merit further studies regarding how it is recruited to genomic loci affecting epigenetic regulation.

\section{Conclusions}

This study presents for the first time the DNA methylation dynamics of the principal genes orchestrating the myogenic determination and differentiation programs during myogenesis. Our results show that a common DNA demethylation signature is required to acquire and maintain the muscle-cell identity, and that downregulation of the muscle-specific cytidine deaminase Apobec2 in ES-derived myogenic precursors reduces myogenicassociated DNA demethylation and impairs muscle differentiation. Importantly, we have also identified muscle epigenetic markers that may be useful to ensure the efficient and safe generation of ES- and iPS-derived myogenic progenitors for therapeutic applications.

\section{Methods}

Skeletal muscle stem cells isolation and culture

Skeletal muscle stem cells were isolated from hind limb muscles of 6 - to 8 -week-old mice (kindly provided by P. Muñoz Cánoves of the Pompeu Fabra University, Barcelona) as described in [75]. After mechanical and enzymatic dissociation with $1 \%$ Pronase protease (Calbiochem), the filtered digest was centrifuged through an isotonic Percoll (Amersham) gradient (60\% overlaid with $20 \%$ ) and cells were collected from the gradient interface, resuspended in growth medium (GM: Ham's F-10 plus $20 \% \mathrm{FBS}, 5 \mathrm{ng} / \mathrm{ml} \mathrm{bFGF}, 100 \mathrm{U} / \mathrm{ml}$ penicillin and $100 \mu \mathrm{g} / \mathrm{ml}$ streptomycin) and grown on tissue culture dishes coated with $0.05 \mathrm{mg} / \mathrm{ml}$ collagen I from rat tail (Becton and Dickinson) to amplify the myoblast population. To induce myotube formation, confluent proliferating primary myoblasts were grown on matrigel coated 
culture dishes (Basement Membrane Matrix, Becton and Dickinson) and switched to differentiation medium the next day (DM: DMEM plus $2 \%$ horse serum, $100 \mathrm{U} / \mathrm{ml}$ penicillin and $100 \mu \mathrm{g} / \mathrm{ml}$ streptomycin (Life Technologies)) for 4 days. Myofibres directly isolated from EDL muscles were kindly provided by S. Gutarra. Two biological replicates of each experiment were performed and analysed. Mouse protocols were approved by the Animal Care and Use Committee of the PRBB, and the Ethical Committee for Animal Experimentation of the Government of Catalonia.

\section{Cell lines}

ESCs were kindly provided by M. Carrió (cGR8) and F. Lluís (E14Tg2), NPCs were also provided by F. Lluís and HL1 cells by S. Pagans. MEFs and HEK $293 \mathrm{~T}$ cells were cultured in DMEM complemented with $10 \%$ fetal bovine serum, $1 \%$ penicillin/streptomycin and $2 \mathrm{mM}$ Glutamax (Life Technologies).

\section{Inducible Pax7-ESC-derived myogenic model}

The inducible cell line encoding full length murine Pax7 (iPax7) was generated as previously described in [41]. iPax7-ESCs were co-cultured with irradiated mouse embryonic fibroblasts (MEFs), obtained as described in [76]. The co-culture was maintained in knockout DMEM (Invitrogen) supplemented with $15 \%$ ES qualified FBS (Invitrogen), $1 \%$ penicillin/streptomycin (Invitrogen), $2 \mathrm{mM}$ Glutamax, $0.1 \mathrm{mM}$ b-mercaptoethanol and $1000 \mathrm{U} / \mathrm{ml}$ Lif (Millipore) medium. To induce cellular differentiation ESCs were trypsinized, resuspended in EB differentiation medium (EBM) containing Iscovemodified DMEM (Life Technologies), 15 \% ES qualified FBS (Life Technologies), $1 \%$ penicillin/streptomycin, $2 \mathrm{mM}$ Glutamax, $200 \mathrm{mg} / \mathrm{ml}$ iron-saturated transferrin (Sigma-Aldrich), $4.5 \mathrm{mM}$ monothioglycerol (Sigma-Aldrich, and $50 \mathrm{mg} / \mathrm{ml}$ ascorbic acid (SigmaAldrich), and preplated for $30 \mathrm{~min}$ on gelatin-coated dishes to remove MEFs. After counting, $1 \times 10^{6}$ cells were plated in $15 \mathrm{~cm}$ petri dishes and placed on a shaker at $60 \mathrm{RPM} / \mathrm{min}\left(37{ }^{\circ} \mathrm{C}, 5 \% \mathrm{CO}_{2}\right)$ to induce $\mathrm{EB}$ formation (this time point is referred to as day 0 of the EB differentiation protocol). Pax7 expression was induced after 3 days of differentiation by adding doxycycline (Dox) (D9891, Sigma-Aldrich) to the culture medium at a final concentration of $1 \mu \mathrm{g} / \mathrm{ml}$. At day 5 , mesodermal precursors corresponding to the $\mathrm{PDGFR \alpha} \alpha^{+} / \mathrm{FLK} 1^{-}$cell population were isolated by FACS (FACS Aria II - BD Biosciences) using PE-conjugated anti-mouse CD140a (PDGFR $\alpha$; RRID: AB_657615) and APC-conjugated anti-mouse CD309 (FLK1; RRID: AB_657865) (E-Bioscience). Sorted cells from Dox-treated and untreated EBs were cultured on gelatin-coated flasks in EBM (with or without Dox) for 5 more days before harvesting them (which we refer to as iPax7 myoblasts (MB) precursor cells). To induce the myotube formation, the $\mathrm{i} P \mathrm{Ax} 7-\mathrm{MB}$ precursors were cultured on DMEM (Invitrogen) supplemented with $2 \%$ horse serum (Hyclone), $1 \%$ penicillin/streptomycin and $2 \mathrm{mM}$ glutamax and, importantly, Dox was removed to allow terminal myogenic differentiation, which physiologically only occurs upon Pax7 expression withdrawal.

\section{Lentiviral transduction}

Apobec2 shRNAs cloned in pLKO.1-puro lentiviral constructs were purchased by the Biomedical Genomic Center at the University of Minnesota. After testing different clones for Apobec2 down-regulation compared to the control vector, the following clones were selected: shRNA\#1 CCTGGCTTCCTGATTCTACTT and shRNA\#4 GCTA CCAGTCAACTTCTTCAA. Lentiviruses were produced by co-transfecting pLKO.1-puromycine vector and the packaging constructs (pVSV-G, pREV and pD8.74 [77]) in HEK 293 T cells using Lipofectamine LTX-Plus Reagent (Life Technologies) following the manufacturer's instruction. Supernatants containing the lentiviral particles were collected $36 \mathrm{~h}$ after transfection, passed through a $0.45 \mu \mathrm{m}$ filter and used to transduce $\mathrm{i} P a x 7$ $\mathrm{MB}$ precursors. Cells were harvested for gene expression and DNA methylation analyses 4 days after transduction.

\section{Gene expression analysis}

Total RNA was isolated with a miRNeasy Mini Kit (Qiagen) according to the manufacturer's instructions and retro-transcribed with SuperScript ${ }^{\circ}$ III Reverse Transcriptase (Life Technologies). cDNA was amplified by qRT-PCR using LightCycler480 (Roche) with Fast Start DNA Master Sybr Green I mix (Roche) and expression results were normalized with Gapdh or $18 S$ expression. Expression results for the Pax7-induced ES-derived muscle differentiation model were plotted relative to iPax7 myogenic precursors (set to 1) for myogenic markers and to iPax7-ESC for pluripotency markers. Primer sequences are listed in Additional file 6.

\section{Immunofluorescence staining}

Cells cultured on slides were fixed with $4 \%$ paraformaldehyde for 10 min, permeabilized with $0.1 \%$ Triton X100 (Life Technologies) for $10 \mathrm{~min}$ and blocked with $5 \%$ BSA reagent (Vector Labs) for $30 \mathrm{~min}$, before incubating with primary antibodies Myogenin (1:250, clone F5D, BD Biosciences; RRID: AB_39638) and MHC (1:20, clone MF20, Developmental Studies Hybridoma Bank; RRID: AB_2147781). Alexafluor 555-goat antimouse (1:500, Invitrogen; RRID: AB_2535844) was used as secondary antibody and preparations were mounted with Prolong mounting media with DAPI (Life Technologies) to counter stain nuclei. 


\section{Sodium bisulphite conversion, sequencing and} pyrosequencing validation

Genomic DNA was isolated after an overnight Proteinase $\mathrm{K}$ digestion (Invitrogen) followed by an RNaseA (Invitrogen) treatment for $1 \mathrm{~h}$. After phenol-chloroform extraction, ethanol precipitation and NanoDrop quantification, genomic DNA was run in a $1 \%$ agarose gel stained with ethidium bromide to check its integrity. Sodium bisulphite conversion was performed using 300 ng of genomic DNA with an EZ DNA MethylationGold $^{\mathrm{Tm}}$ Kit (ZymoResearch, Orange) according to the manufacturer's instructions. Treated DNA was amplified as previously described [78], purified and sequenced by Sanger direct sequencing. In Additional file 7 the specific primers for the methylation profiling of the different genomic regions are listed. In Additional file 8 it is shown how the DNA methylation range was quantified and the corresponding validation by pyrosequencing. Briefly, to assess the DNA methylation state of each cytosine we analysed the raw sequencing electropherograms visualized with Geospiza FinchTV software. We compared the DNA reference sequence with the obtained sequence after bisulphite conversion. In bisulphite-treated DNA followed by PCR amplification the methylated cytosines remain cytosines ( $C$, blue peak in the sequencing electropherogram), whereas the unmethylated cytosines become thymines ( $T$, red peak in the sequencing electropherogram). Notice that when reverse sequencing primers are used the cytosines will be read as guanines (G, black peak) and the thymines as adenines (A, green peak). When a single peak was observed in the original $\mathrm{C}$ position, we considered the population homogenous, indicating a blue peak $(C)$ that the cytosine was methylated in all cells and a red peak $(\mathrm{T})$ that the cytosine was unmethylated in all cells. When two peaks were shown in the original $\mathrm{C}$ position it corresponded to a mixed population. In these cases, the height of each peak was measured to assess the proportion of each population. For the sake of simplicity, the methylation level was ranked in five different intervals $0-0.2$, $0.21-0.4,0.41-0.6,0.61-0.8$ and $0.81-1$, which reflected the DNA methylation state of this particular cytosine. In Additional file $8 \mathrm{~b}$ the pyrosequencing validation of the methylation state of three CpGs located in Myh1 and Myh8 promoter regions is shown. Notably, the linear correlation between the results obtained by both methodologies was $R^{2}=0.98$ for Myh1 and $R^{2}=0.91$ for Myh8.

\section{Western blot analysis}

Proteins were extracted using RIPA buffer supplemented with protease inhibitors (Complete Mini, Roche) and quantified using Bradford reagent (Sigma). An amount of $50 \mathrm{ug}$ of proteins were separated on a $12 \%$ SDSPAGE gel and successively transferred on PVDF membrane (Millipore). The membrane was blocked using $5 \%$
BSA in TBST and then incubated overnight with the indicated antibody diluted in blocking solution. Antibodies used were: anti-Apobec2 (1:1000, sc-98335 Santa Cruz Biotechnology; RRID: AB_2258415), anti-MyoG (1:1000, clone F5D Developmental Studies Hybridoma Bank; RRID: AB_2146602), and anti-Actin (1:2000, MAB1501 Millipore; RRID: AB_2223041). HRP-conjugated antimouse or anti-rabbit IgG (1:20000, Amersham ECL Western Blotting Reagent Pack RPN2124) were used as secondary antibodies. Positive and negative controls used for the identification of Apobec 2 consisted of skeletal muscle and brain protein extracts, respectively.

\section{Availability of data and materials}

All genomic representations containing reference genes, CpG islands and ChIP-seq data were integrated, explored and visualized using the Integrative Genomics Viewer [79]. All ChIP-seq data, with the exception of the H3K27Ac and p300 data from proliferating and differentiated $\mathrm{C} 2 \mathrm{C} 12$ (MB and MT) [38], were generated by the ENCODE Project Consortium [37]. GEO accession numbers are listed in Additional file 9. Sodium bisulphite sequencing data and Kruskal-Wallis test of sodium bisulphite data were done with the Methylation Plotter web tool [80]. Supporting data containing the individual gene expression values are shown in Additional file 10.

\section{Additional files}

\begin{tabular}{|c|}
\hline $\begin{array}{l}\text { Additional file 1: CpG-island promoters of developmental genes are } \\
\text { unmethylated. DNA methylation state of CpG islands overlapping and } \\
\text { surrounding the promoter region of Pax3 (a) and Pax (b) genes in } \\
\text { myogenic (MB, MT, MF) and non-myogenic samples (ESC). CpG islands } \\
\text { are indicated in green and regions analysed by sodium bisulphite } \\
\text { sequencing are shown in red. Each circle represents a CpG dinucleotide and } \\
\text { its distance to the gene TSS is indicated below. The colour gradient } \\
\text { represents the percentage of methylation indicated in the legend. } \\
\text { Abbreviations: ESC, embryonic stem cell; MB, myoblast; MT, myotube; } \\
\text { MF, myofiber; TSS, transcription start site. C. DNA methylation state of -5 kb } \\
\text { distal regulatory region for MyoD was analysed by sodium bisulphite } \\
\text { sequencing in ESC and myoblast samples, and represented as above. } \\
\text { (PDF } 171 \mathrm{~kb} \text { ) }\end{array}$ \\
\hline $\begin{array}{l}\text { Additional file 2: CpG-poor promoters of pluripotency genes became } \\
\text { methylated during muscle-lineage specification. a. Scheme of the Sox2 } \\
\text { and Fgf4 loci showing in dark green the CpG island and in light green } \\
\text { the unmethylated state of the analysed CpGs by HAIB-Methyl RRBS from } \\
\text { ENCODE Project in human ESCS (H1-ESCS), myoblasts (HSMM), myotubes } \\
\text { (HSMMtube) and myofibers (skeletal_7N). b. DNA methylation state of } \\
\text { Pou5f1 (left) and Dppa4 (right) promoters in myogenic (MB, MT, MF) and } \\
\text { non-myogenic samples (ESC, NPC, HL1, MEF). Analysed regions are } \\
\text { indicated in red and biological duplicates are shown in the circle } \\
\text { charts, where each circle represents a CpG dinucleotide and its distance to } \\
\text { the gene TSS is indicated below. The colour gradient represents the } \\
\text { percentage of methylation indicated in the legend. Bar charts show the } \\
\text { gene expression values measured by qRT-PCR and normalized by Gapdh } \\
\text { and 18S, respectively (n=2, mean } \pm \text { SD). N.D. means non detectable. C. } \\
\text { Histone marks distribution and p300 binding in ESC (blue), MB (yellow) and } \\
\text { MT (red) obtained from ENCODE Project and Dynlatch's lab [38]. Abbreviations: } \\
\text { ESC, embryonic stem cell; HL1, cardiomyocyte; MB, myoblast; MT, myotube; } \\
\text { MF, myofiber; MEF, mouse embryonic fibroblast; NPC, neuronal } \\
\text { precursor cell; TSS, transcription start site. (PDF 153 kb) }\end{array}$ \\
\hline
\end{tabular}


Additional file 3: Pax7-induced ESC-derived myogenic model. Representative fields showing the morphology of iPax7 ES-derived cells at different stages of differentiation with or without Pax7 induction (100x magnification). Arrows show plurinucleated myotubes. ESCs, $M B$ and $M T$ precursors were cultured in monolayer, whereas EBs day 3 were grown in suspension. Abbreviations: EBs, embryoid bodies; ESCs, embryonic stem cells; MB, myoblast; MT, myotube; iPax7, inducible Pax7; Dox, Doxycycline. (PDF 25026 kb)

Additional file 4: Dnmt and Tet expression profiles during Pax7-induced ESC derived myogenic model and Apobec2 western blot analysis. Expression levels of Dnmt1, Dnmt3a and Dnmt3b (a) and Tet1, Tet2 and Tet3 (b) were measured by qRT-PCR at the successive time points of iPaxt ESC-derived myogenic model, with or without doxycycline, and normalized by Gapdh expression ( $n=3$, mean \pm SD). c. Apobec2 western blots were performed on total protein extracts from skeletal muscle tissue (SK M) and brain (left), and muscle progenitor cells (iPax7-MB) and mature myotubes (C2C12-MT) (right). Skeletal muscle shows a specific Apobec2 band $(32 \mathrm{kDa})$, whereas multiple bands are detected in brain tissue and in muscle cells. (PDF $798 \mathrm{~kb}$ )

Additional file 5: DNA methylation analysis of MyoD and Myf5 genes in Apobec2 depleted cells. DNA methylation analysis by sodium bisulphite sequencing of the $-20 \mathrm{~kb} M y o D$ enhancer (a) and promoter and $-111 \mathrm{~kb}$ enhancer of Myf5 gene (b) in Pax7 ES-derived myogenic precursors transduced with Apobec2 shRNA1 and shRNA4, in three biological replicates. Each circle represents a CpG dinucleotide and its distance to the gene TSS is indicated below. The colour gradient represents the methylation level indicated in the legend. (PDF $100 \mathrm{~kb}$ )

Additional file 6: Primer sequences used by GRT-PCR expression analysis. (DOCX $12 \mathrm{~kb}$ )

Additional file 7: Primer sequences used by assessing the DNA methylation profiles of different genomic regions either by Sanger sequencing or pyrosequencing. (DOCX $16 \mathrm{~kb}$ )

Additional file 8: Explanation and validation of the Sanger sequencingbased DNA methylation method. a. Quantification of DNA methylation state by bisulphite conversion followed by Sanger direct sequencing. DNA methylation state of each cytosine was analysed comparing the DNA reference sequence with the raw sequencing electropherograms of the bisulphite-converted sequence, visualized with Geospiza FinchTV software. The methylation level was ranked in five different intervals $0-0.2,0.21-0.4,0.41-0.6,0.61-0.8$ and $0.81-1$, which reflects the DNA methylation state of this particular cytosine. Detailed explanations about how the methylation interval was assigned for each cytosine are in the Methods section. b. Correlation between Sanger and Pyrosequencing results. In the left panels are shown the DNA methylation state of three CpGs located in Myh1 and Myh8 promoter regions, in two embryonic stem cells ESC 1-2 and two primary myogenic precursor cells MPC 1-2. For each $\mathrm{CpG}$ it is shown the raw chromatogram obtained by Sanger sequencing with our corresponding assigned methylation interval and the methylation value obtained by pyrosequencing, which is inside the interval in most of the cases (right top scatter plots). On the right bottom scatter plots are shown the high linear correlation between Sanger sequencing and pyrosequencing results, with $R^{2}=0,98$ for Myh1 and $R^{2}=0,91$ for Myh8. (PDF $2930 \mathrm{~kb}$ )

Additional file 9: GEO accession numbers for histone marks ChIP-seq data generated by the ENCODE Project Consortium and Dynlacht's laboratory. (DOCX $43 \mathrm{~kb}$ )

Additional file 10: Individual gene expression values normalized by a reference gene are shown for the two or three biological replicates analysed. (XLSX 49 kb)

\section{Abbreviations}

CGI: CpG island; Dox: Doxycycline; EB: Embryoid body; ESCs: Embryonic stem cells; iPax7: Inducible Pax7; MB: Myoblasts; MF: Myofibres; MT: Myotubes.

\section{Competing interests}

The authors declare that they have no competing interests.

\section{Authors' contributions}

EC: design, performance, data analysis and interpretation, and manuscript writing. AM: design, performance and interpretation. MM: technical assistance. MAP and RP: conception and design. MS: conception and design and manuscript writing. All authors read and approved the final manuscript.

\section{Acknowledgements}

We thank Irene López, Jessica Acosta, Dèlia Yubero and Ruth Montalbo for excellent technical assistance. We also thank Dr. Reuben Harris (University of Minnesota) for his advice on Apobec2 western blot. We are also grateful to Sonia Forcales for helpful discussions. E.C. is a FPI Fellow (MINECO). This work was supported by Ministerio de Economía y Competitividad (SAF201237427 to M.S., SAF2011-23638 and SAF2015-64521 to M.A.P.), Feder funds, Generalitat de Catalunya (2009 SGR1356 to M.A.P.), National Institutes of Health grant (R01 AR055299 (R.P.) and Minnesota Regenerative Medicine grant (MRM 2015 PDSCH 003 to A.M).

\section{Author details}

${ }^{1}$ Institut de Medicina Predictiva i Personalizada del Càncer (IMPPC) and Institut Germans Trias i Pujol (IGTP), Campus Can Ruti, 08916 Badalona, Spain. ${ }^{2}$ Lillehei Heart Institute, Department of Medicine, University of Minnesota, Minneapolis 55455, USA.

\section{Received: 5 February 2016 Accepted: 23 March 2016}

Published online: 13 April 2016

\section{References}

1. Mohn F, Schübeler D. Genetics and epigenetics: stability and plasticity during cellular differentiation. Trends in Genetics. 2009;25(3):129-36. doi:10. 1016/j.tig.2008.12.005.

2. Berdasco M, Esteller M. DNA methylation in stem cell renewal and multipotency. Stem Cell Res Ther. 2011;2(5):42. doi:10.1186/scrt83.

3. Cedar H, Bergman Y. Programming of DNA methylation patterns. Annu Rev Biochem. 2012;2012(81):97-117. doi:10.1146/annurev-biochem-052610-91920.

4. Smith ZD, Meissner A. DNA methylation: roles in mammalian development. Nat Rev Genet. 2013;14(3):204-20. doi:10.1038/nrg3354

5. Jones PA. Functions of DNA methylation: islands, start sites, gene bodies and beyond. Nat Rev Genet. 2012;13(7):484-92. doi:10.1038/nrg3230.

6. Rakyan VK, Down TA, Thorne NP, Flicek P, Kulesha E, Graf S, et al. An integrated resource for genome-wide identification and analysis of human tissue-specific differentially methylated regions (tDMRs). Genome Res. 2008; 18(9):1518-29. doi:10.1101/gr.077479.108.

7. Straussman R, Nejman D, Roberts D, Steinfeld I, Blum B, Benvenisty N, et al. Developmental programming of $\mathrm{CpG}$ island methylation profiles in the human genome. Nat Struct Mol Biol. 2009;16(5):564-71. doi:10.1038/nsmb. 1594.

8. Fernandez AF, Assenov Y, Martin-Subero Jl, Balint B, Siebert R, Taniguchi H, et al. A DNA methylation fingerprint of 1628 human samples. Genome Res. 2012;22(2):407-19. doi:10.1101/gr.119867.110.

9. Nagae G, Isagawa T, Shiraki N, Fujita T, Yamamoto S, Tsutsumi S, et al. Tissue-specific demethylation in CpG-poor promoters during cellular differentiation. Hum Mol Genet. 2011;20(14):2710-21. doi:10.1093/hmg/ ddr170.

10. Liang P, Song F, Ghosh S, Morien E, Qin M, Mahmood S, et al. Genomewide survey reveals dynamic widespread tissue-specific changes in DNA methylation during development. BMC Genomics. 2011;12(1):231. doi:10. 1186/1471-2164-12-231.

11. Lister R, Pelizzola M, Dowen RH, Hawkins RD, Hon G, Tonti-Filippini J, et al. Human DNA methylomes at base resolution show widespread epigenomic differences. Nature. 2009:462(7271):315-22. doi:10.1038/nature08514.

12. Ji H, Ehrlich LI, Seita J, Murakami P, Doi A, Lindau P, et al. Comprehensive methylome map of lineage commitment from haematopoietic progenitors. Nature. 2010;467(7313):338-42. doi:10.1038/nature09367.

13. Laurent L, Wong E, Li G, Huynh T, Tsirigos A, Ong CT, et al. Dynamic changes in the human methylome during differentiation. Genome Research. 2010;20(3):320-31. do:10.1101/gr.101907.109.

14. Isagawa T, Nagae G, Shiraki N, Fujita T, Sato N, Ishikawa S, et al. DNA methylation profiling of embryonic stem cell differentiation into the three germ layers. PLoS One. 2011;6(10):e26052. doi:10.1371/journal.pone.0026052. 
15. Xie W, Schultz MD, Lister R, Hou Z, Rajagopal N, Ray P, et al. Epigenomic analysis of multilineage differentiation of human embryonic stem cells. Cell. 2013;153(5):1134-48. doi:10.1016/j.cell.2013.04.022.

16. Carrio E, Diez-Villanueva A, Lois S, Mallona I, Cases I, Forn M, et al. Deconstruction of DNA methylation patterns during myogenesis reveals specific epigenetic events in the establishment of the skeletal muscle lineage. Stem Cells. 2015;10:2015.

17. Tahiliani M, Koh KP, Shen Y, Pastor WA, Bandukwala H, Brudno Y, et al. Conversion of 5-methylcytosine to 5-hydroxymethylcytosine in mammalian DNA by MLL partner TET1. Science. 2009;324(5929):930-5. doi:10.1126/ science.1170116.

18. Ito S, D'Alessio AC, Taranova OV, Hong K, Sowers LC, Zhang Y. Role of Tet proteins in $5 \mathrm{mC}$ to $5 \mathrm{hmC}$ conversion, ES-cell self-renewal and inner cell mass specification. Nature. 2010;466(7310):1129. 33

19. Morgan HD, Dean W, Coker HA, Reik W, Petersen-Mahrt SK. Activationinduced cytidine deaminase deaminates 5-methylcytosine in DNA and is expressed in pluripotent tissues: implications for epigenetic reprogramming. J Biol Chem. 2004;279(50):52353-60.

20. Bhutani N, Brady JJ, Damian M, Sacco A, Corbel SY, Blau HM. Reprogramming towards pluripotency requires AID-dependent DNA demethylation. Nature. 2010;463(7284):1042-7. doi:10.1038/nature08752.

21. Guo JU, Su Y, Zhong C, Ming GL, Song H. Emerging roles of TET proteins and 5-hydroxymethylcytosines in active DNA demethylation and beyond. Cell Cycle. 2011;10(16):2662-8.

22. Zhang F, Pomerantz JH, Sen G, Palermo AT, Blau HM. Active tissue-specific DNA demethylation conferred by somatic cell nuclei in stable heterokaryons. Proc Natl Acad Sci U S A. 2007;104(11):4395-400. doi:10. 1073/pnas.0700181104

23. Garcia-Prat L, Sousa-Victor P, Munoz-Canoves P. Functional dysregulation of stem cells during aging: a focus on skeletal muscle stem cells. FEBS J. 2013; 280(17):4051-62. doi:10.1111/febs.12221.

24. Buckingham M, Rigby PW. Gene regulatory networks and transcriptional mechanisms that control myogenesis. Dev Cell. 2014;28(3):225-38.

25. Kassar-Duchossoy L, Giacone E, Gayraud-Morel B, Jory A, Gomes D, Tajbakhsh S. Pax3/Pax7 mark a novel population of primitive myogenic cells during development. Genes Dev. 2005;19(12):1426-31.

26. Relaix F, Rocancourt D, Mansouri A, Buckingham M. A Pax3/Pax7-dependent population of skeletal muscle progenitor cells. Nature. 2005;435(7044):94853. doi:10.1038/nature03594.

27. Seale P, Sabourin LA, Girgis-Gabardo A, Mansouri A, Gruss P, Rudnicki MA. Pax7 is required for the specification of myogenic satellite cells. Cell. 2000; 102(6):777-86.

28. Jones PA, Wolkowicz MJ, Rideout WM, Gonzales FA, Marziasz CM, Coetzee GA, et al. De novo methylation of the MyoD1 CpG island during the establishment of immortal cell lines. Proc Natl Acad Sci USA. 1990;87(16):6117-21.

29. Bird AP. CpG-rich islands and the function of DNA methylation. Nature. 1986:321(6067):209-13.

30. Gardiner-Garden M, Frommer M. CpG islands in vertebrate genomes. J Mol Biol. 1987;196(2):261-82

31. Illingworth RS, Bird AP. CpG islands-'a rough guide'. FEBS Lett. 2009;583(11): 1713-20. doi:10.1016/j.febslet.2009.04.012.

32. Brunk BP, Goldhamer DJ, Emerson Jr CP. Regulated demethylation of the myoD distal enhancer during skeletal myogenesis. Dev Biol. 1996;177(2):490-503.

33. Chen JC, Love CM, Goldhamer DJ. Two upstream enhancers collaborate to regulate the spatial patterning and timing of MyoD transcription during mouse development. Dev Dyn. 2001;221(3):274-88.

34. Chen JC, Ramachandran R, Goldhamer DJ. Essential and redundant functions of the MyoD distal regulatory region revealed by targeted mutagenesis. Dev Biol. 2002;245(1):213-23.

35. Brown CB, Engleka KA, Wenning J, Min Lu M, Epstein JA. Identification of a hypaxial somite enhancer element regulating Pax3 expression in migrating myoblasts and characterization of hypaxial muscle Cre transgenic mice. Genesis. 2005;41(4):202-9. doi:10.1002/gene.20116.

36. Wen Y, Bi P, Liu W, Asakura A, Keller C, Kuang S. Constitutive Notch activation upregulates Pax7 and promotes the self-renewal of skeletal muscle satellite cells. Mol Cell Biol. 2012;32(12):2300-11. doi:10.1128/MCB.06753-11.

37. Dunham I. An integrated encyclopedia of DNA elements in the human genome. Nature. 2012;489(7414):57-74.

38. Blum R, Vethantham V, Bowman C, Rudnicki M, Dynlacht BD. Genome-wide identification of enhancers in skeletal muscle: the role of MyoD1. Genes Dev. 2012;26(24):763-79.
39. Azuara V, Perry P, Sauer S, Spivakov M, Jorgensen HF, John RM, et al. Chromatin signatures of pluripotent cell lines. Nat Cell Biol. 2006;8(5):532-8.

40. Bernstein BE, Mikkelsen TS, Xie X, Kamal M, Huebert DJ, Cuff J, et al. A bivalent chromatin structure marks key developmental genes in embryonic stem cells. Cell. 2006;125(2):315-26.

41. Darabi R, Santos FN, Filareto A, Pan W, Koene R, Rudnicki MA, et al. Assessment of the myogenic stem cell compartment following transplantation of Pax3/Pax7-induced embryonic stem cell-derived progenitors. Stem Cells. 2011;29(5):777-90. doi:10.1002/stem.625.

42. Carrio E, Suelves M. DNA methylation dynamics in muscle development and disease. Front Aging Neurosci. 2015;5(7):19. doi:10.3389/fnagi.2015. 00019.

43. Mohn F, Weber M, Rebhan M, Roloff TC, Richter J, Stadler MB, et al. LineageSpecific Polycomb Targets and De Novo DNA Methylation Define Restriction and Potential of Neuronal Progenitors. Molecular Cell. 2008;30(6): 755-66. doi:10.1016/j.molcel.2008.05.007.

44. Brunner AL, Johnson DS, Kim SW, Valouev A, Reddy TE, Neff NF, et al. Distinct DNA methylation patterns characterize differentiated human embryonic stem cells and developing human fetal liver. Genome Research. 2009;19(6):1044-56. doi:10.1101/gr.088773.108.

45. Bock C, Beerman I, Lien WH, Smith ZD, Gu H, Boyle P, et al. DNA methylation dynamics during in vivo differentiation of blood and skin stem cells. Mol Cell. 2012;47(4):633-47. doi:10.1016/j.molcel.2012.06.019.

46. Gilsbach R, Preissl S, Gruning BA, Schnick T, Burger L, Benes V, et al. Dynamic DNA methylation orchestrates cardiomyocyte development, maturation and disease. Nat Commun. 2014;5:5288.

47. Palacios D, Mozzetta C, Consalvi S, Caretti G, Saccone V, Proserpio V, et al. TNF/p38a/Polycomb Signaling to Pax7 Locus in Satellite Cells Links Inflammation to the Epigenetic Control of Muscle Regeneration. Cell Stem Cell. 2010;7(4):455-69. doi:10.1016/j.stem.2010.08.013.

48. Oikawa Y, Omori R, Nishii T, Ishida Y, Kawaichi M, Matsuda E. The methylCpG-binding protein CIBZ suppresses myogenic differentiation by directly inhibiting myogenin expression. Cell Res. 2011. doi:10.1038/cr.2011.90.

49. Caretti G, Di Padova M, Micales B, Lyons GE, Sartorelli V. The Polycomb Ezh2 methyltransferase regulates muscle gene expression and skeletal muscle differentiation. Genes Dev. 2004;18(21):2627-38. doi:10.1101/gad.1241904.

50. Seenundun S, Rampalli S, Liu Q-C, Aziz A, Palii C, Hong S, et al. UTX mediates demethylation of $\mathrm{H} 3 \mathrm{~K} 27 \mathrm{me} 3$ at muscle-specific genes during myogenesis. The EMBO Journal. 2010;29(8):1401-11. doi:10.1038/emboj. 2010.37.

51. Gifford CA, Ziller MJ, Gu H, Trapnell C, Donaghey J, Tsankov A, et al. Transcriptional and epigenetic dynamics during specification of human embryonic stem cells. Cell. 2013;153(5):1149-63. doi:10.1016/j.cell.2013.04.037.

52. Zhang $W$, Behringer RR, Olson EN. Inactivation of the myogenic bHLH gene MRF4 results in up-regulation of myogenin and rib anomalies. Genes Dev. 1995;9(11):1388-99.

53. Arnold HH, Braun T. Genetics of muscle determination and development. Curr Top Dev Biol. 2000;48:129-64.

54. Sambasivan R, Comai G, Le Roux I, Gomes D, Konge J, Dumas G, et al. Embryonic founders of adult muscle stem cells are primed by the determination gene Mrf4. Dev Biol. 2013;381(1):241-55. doi:10.1016/j.ydbio. 2013.04.018

55. Buckingham M, Relaix F. The Role ofPaxGenes in the Development of Tissues and Organs:Pax3andPax7Regulate Muscle Progenitor Cell Functions. Annual Review of Cell and Developmental Biology. 2007;23(1):645-73. doi: 10.1146/annurev.cellbio.23.090506.123438.

56. Soleimani VD, Punch VG, Kawabe $Y$, Jones AE, Palidwor GA, Porter CJ, et al. Transcriptional dominance of Pax7 in adult myogenesis is due to highaffinity recognition of homeodomain motifs. Dev Cell. 2012;22(6):1208-20. doi:10.1016/j.devcel.2012.03.014.

57. McKinnell IW, Ishibashi J, Le Grand F, Punch VG, Addicks GC, Greenblatt JF, et al. Pax7 activates myogenic genes by recruitment of a histone methyltransferase complex. Nat Cell Biol. 2008;10(1):77-84. doi:10.1038/ ncb1671.

58. Simone C, Forcales SV, Hill DA, Imbalzano AN, Latella L, Puri PL. p38 pathway targets SWI-SNF chromatin-remodeling complex to muscle-specific loci. Nat Genet. 2004;36(7):738-43. doi:10.1038/ng1378.

59. de la Serna IL, Ohkawa Y, Berkes CA, Bergstrom DA, Dacwag CS, Tapscott SJ, et al. MyoD targets chromatin remodeling complexes to the myogenin locus prior to forming a stable DNA-bound complex. Mol Cell Biol. 2005; 25(10):3997-4009 
60. Puri PL, Sartorelli V, Yang XJ, Hamamori Y, Ogryzko W, Howard BH, et al. Differential roles of p300 and PCAF acetyltransferases in muscle differentiation. Mol Cell. 1997;1(1):35-45.

61. Cao Y, Yao Z, Sarkar D, Lawrence M, Sanchez GJ, Parker MH, et al. Genomewide MyoD Binding in Skeletal Muscle Cells: A Potential for Broad Cellular Reprogramming. Developmental Cell. 2010;18(4):662-74. doi:10.1016/j. devcel.2010.02.014.

62. Mozzetta C, Consalvi S, Saccone V, Forcales SV, Puri PL, Palacios D. Selective control of Pax7 expression by TNF-activated p38alpha/polycomb repressive complex 2 (PRC2) signaling during muscle satellite cell differentiation. Cell Cycle. 2011;10(2):191-8.

63. Liao W, Hong SH, Chan BH, Rudolph FB, Clark SC, Chan L. APOBEC-2, a cardiac- and skeletal muscle-specific member of the cytidine deaminase supergene family. Biochem Biophys Res Commun. 1999;260(2):398-404.

64. Anant S, Mukhopadhyay D, Sankaranand V, Kennedy S, Henderson JO, Davidson NO. ARCD-1, an apobec-1-related cytidine deaminase, exerts a dominant negative effect on C to U RNA editing. Am J Physiol Cell Physiol. 2001;281(6):C1904-16.

65. Mikl MC, Watt IN, Lu M, Reik W, Davies SL, Neuberger MS, et al. Mice deficient in APOBEC2 and APOBEC3. Mol Cell Biol. 2005;25(16):7270-7. doi: 10.1128/MCB.25.16.7270-7277.2005.

66. Sato Y, Probst HC, Tatsumi R, Ikeuchi Y, Neuberger MS, Rada C. Deficiency in APOBEC2 leads to a shift in muscle fiber type, diminished body mass, and myopathy. J Biol Chem. 2010;285(10):7111-8. doi:10.1074/jbc.M109.052977.

67. Harris RS, Petersen-Mahrt SK, Neuberger MS. RNA editing enzyme APOBEC1 and some of its homologs can act as DNA mutators. Mol Cell. 2002;10(5): 1247-53.

68. Lada AG, Krick CF, Kozmin SG, Mayorov VI, Karpova TS, Rogozin IB, et al. Mutator effects and mutation signatures of editing deaminases produced in bacteria and yeast. Biochemistry. 2011;76(1):131-46.

69. Nabel CS, Jia H, Ye Y, Shen L, Goldschmidt HL, Stivers JT, et al. AID/APOBEC deaminases disfavor modified cytosines implicated in DNA demethylation. Nat Chem Biol. 2012:8(9):751-8. doi:10.1038/nchembio.42.

70. Rai K, Huggins IJ, James SR, Karpf AR, Jones DA, Cairns BR. DNA demethylation in zebrafish involves the coupling of a deaminase, a glycosylase, and gadd45. Cell. 2008;135(7):1201-12. doi:10.1016/j.cell.2008.11. 042.

71. Vonica A, Rosa A, Arduini BL, Brivanlou AH. APOBEC2, a selective inhibitor of TGFbeta signaling, regulates left-right axis specification during early embryogenesis. Dev Biol. 2011;350(1):13-23. doi:10.1016/j.ydbio.2010.09.016.

72. Powell C, Elsaeidi F, Goldman D. Injury-dependent Muller glia and ganglion cell reprogramming during tissue regeneration requires Apobec2a and Apobec2b. J Neurosci. 2012;32(3):1096-109.

73. Powell C, Grant AR, Cornblath E, Goldman D. Analysis of DNA methylation reveals a partial reprogramming of the Muller glia genome during retina regeneration. Proc Natl Acad Sci U S A. 2013;110(49):19814-9. doi:10.1073/ pnas.1312009110.

74. Rudnicki MA, Schnegelsberg PN, Stead RH, Braun T, Arnold HH, Jaenisch R. MyoD or Myf-5 is required for the formation of skeletal muscle. Cell. 1993; 75(7):1351-9.

75. Suelves M, Vidal B, Serrano AL, Tjwa M, Roma J, Lopez-Alemany R, et al. UPA deficiency exacerbates muscular dystrophy in MDX mice. J Cell Biol. 2007; 178(6):1039-51. doi:10.1083/jcb.200705127.

76. Jozefczuk J, Drews K, Adjaye J. Preparation of mouse embryonic fibroblast cells suitable for culturing human embryonic and induced pluripotent stem cells. J Vis Exp. 2012;21:(64.

77. Follenzi A, Ailles LE, Bakovic S, Geuna M, Naldini L. Gene transfer by lentiviral vectors is limited by nuclear translocation and rescued by HIV-1 pol sequences. Nat Genet. 2000;25(2):217-22.

78. Clark SJ, Statham A, Stirzaker C, Molloy PL, Frommer M. DNA methylation: bisulphite modification and analysis. Nat Protoc. 2006;1(5):2353-64.

79. Robinson JT, Thorvaldsdottir H, Winckler W, Guttman M, Lander ES, Getz G, et al. Integrative genomics viewer. Nat Biotechnol. 2011;29(1):24-6.

80. Mallona I, Diez-Villanueva A, Peinado MA. Methylation plotter: a web tool for dynamic visualization of DNA methylation data. Source Code Biol Med. 2014:7(9):11. doi:10.1186/751-0473-9-11.

\section{Submit your next manuscript to BioMed Central and we will help you at every step:}

- We accept pre-submission inquiries

- Our selector tool helps you to find the most relevant journal

- We provide round the clock customer support

- Convenient online submission

- Thorough peer review

- Inclusion in PubMed and all major indexing services

- Maximum visibility for your research

Submit your manuscript at www.biomedcentral.com/submit
Biomed Central 